\title{
Using monoclonal antibodies to label living root hairs: a novel tool for studying cell wall microarchitecture and dynamics in Arabidopsis
}

\author{
Emily R Larson ${ }^{1,4}$, Mary L Tierney ${ }^{1,2}$, Berke Tinaz ${ }^{3}$ and David S Domozych ${ }^{3 *}$
}

\begin{abstract}
Background: The Arabidopsis root hair represents a valuable cell model for elucidating polar expansion mechanisms in plant cells and the overall biology of roots. The deposition and development of the cell wall is central to the root hair expansion apparatus. During this process, incorporation of specific wall polymers into the growing wall architecture constitutes a critical spatio-temporal event that controls hair size and growth rate and one that is closely coordinated with the cell's endomembrane, cytoskeletal and signal transduction apparatuses.

Results: In this study, the protocol for live cell labeling of roots with monoclonal antibodies that bind to specific wall polymers is presented. This method allows for rapid assessment of root hair cell wall composition during development and assists in describing changes to cell wall composition in transgenic mutant lines. Enzymatic "unmasking" of specific polymers prior to labeling allows for refined interpretation of cell wall chemistry. Live cell immunofluorescence data may also be correlated with transmission electron microscopy-based immunogold labeling.

Conclusions: Live Arabidopsis root hairs may be labeled with cell wall polymer-specific antibodies. This methodology allows for direct visualization of cell wall dynamics throughout development in stable transgenic plant lines. It also provides an important new tool in the elucidation of the specific interactions occurring between membrane trafficking networks, cytoskeleton and the cell wall deposition/remodeling mechanism.
\end{abstract}

Keywords: Arabidopsis, Root hairs, Live cell labeling, Immunocytochemistry, Polar growth, Cell wall

\section{Background}

The expansion dynamics of a plant cell are directly controlled by the microarchitecture of its cell wall. Modulations to cell wall constituents via new polymer deposition and/or remodeling of pre-existing polymers create loosened or "softened" zones with less tensile strength throughout the wall or at specific sites therein. Internal turgor pressure generates the non-vectorial force against the wall that drives the expansion process at these softened zones [1,2]. Many plant cells exhibit diffusive growth whereby growth is roughly equivalent on all faces of the expanding cell. However, other cell types grow in a polar fashion where wall and cell expansion are focused at a specific point or front $[3,4]$. Tensile resistance of the wall to turgor is less at this front, that in turn, allows for a localized but controlled cell

\footnotetext{
* Correspondence: ddomoz@skidmore.edu

${ }^{3}$ Department of Biology, Skidmore College, Saratoga Springs, NY, USA

Full list of author information is available at the end of the article
}

expansion. At other regions of the cell the wall retains sufficient tensile strength to resist turgor-driven pressure. This type of growth often leads to distinct tubular shapes, as exemplified by pollen tubes, root hairs and moss protonemata.

The most well studied polar expansion system in land plants is the pollen tube $[5,6]$. At the tip of a growing tube, pectin dynamics create a less-rigid wall that promotes polarized expansion driven by turgor $[7,8]$. In the shank areas adjacent to the tip, modulation of wall chemistry creates a rigid matrix organization that is resistant to turgor pressure. This includes de-esterification of the pectin followed by calcium $\left(\mathrm{Ca}^{2+}\right)$ complexing to yield a rigid gel and the addition of $ß(1-3)$-glucan (callose) and $ß(1-4)$-glucan (cellulose) to the wall.

Root hairs represent specialized extensions of the root epidermis that are also formed by polar expansion. These structures are profoundly important for the survival of a plant as they are critical for the uptake of 
water and minerals and are involved in the establishment of symbiotic associations with resident microbiota of soils [9-11]. Surprisingly, far less is known about wall composition and architecture, and its role in polar expansion of root hairs than for other polar expanding plant cells. This is due to the exceptionally fragile nature of the hairs, especially when handling during experimental manipulation, and the difficulty in obtaining sufficient amounts of root hair wall material for biochemical studies. Presently, it is thought that cellulose microfibril arrangement is random at the growing root hair tip, which consequently creates a softened zone to promote unidirectional expansion [12,13]. Lateral expansion along the shank of the hair is restricted by the production of a secondary cell wall containing an organized helicoid arrangement of microfibrils that make the wall resistant to turgor pressure [14-17]. To date, only limited information is available concerning the non-cellulosic components that play key roles in tethering microfibrils, and that form the matrix in which the cellulose is embedded [18,19]. This results in an incomplete understanding of the root hair cell wall composition/organization and its required role in polar expansion.

Over the past two decades, the use of monoclonal antibodies (mAbs) with specificity toward epitopes of various cell wall polymers has greatly enhanced our understanding of cell wall chemistry. Employment of mAbs in high throughput microarrays allows for rapid screening of large numbers of polymers in different taxa, tissues, cell types and cell wall fractions [20,21]. Similarly, mAbs have been important in mapping specific polymers in various plants and parts therein using light microscopy (LM)-based immunofluorescnce and transmission electron microscopy (TEM)-based immunogold labeling [22-24]. For virtually all of these studies, cells and tissues are typically fixed using chemical or cryofreezing methods, dehydrated and embedded in a plastic or wax matrix that allows for subsequent sectioning prior to imaging [25]. While these protocols have yielded valuable results, they may cause extraction of polymers, artefact formation and wall damage during preparation. More importantly, these techniques only provide snapshots of the cell wall and limited developmental information dealing with the dynamics of the wall in a live plant. Recently, we have devised live-labeling strategies for green algae using mAbs and other molecular probes [26,27]. These have provided detailed information about wall architecture and wall development during cell expansion in live cells. In this paper, we report on the development of live cell imaging protocol for root hair development in Arabidopsis thaliana. This methodology allows for rapid mapping of cell wall polymers using mAbs with live root hairs, and provides a valuable new technique when coupled with transgenic cell lines for detailed studies dealing with wall deposition, secretory dynamics and cell expansion.

\section{Results}

The protocol developed here for live labeling of root hairs is both simple and convenient, and is outlined in Figure 1. The elimination of fixation, dehydration and embedding is advantageous especially for handling such fragile specimens as root hairs. This methodology also does not require sectioning or dewaxing protocols and allows for 3-dimensional image acquisition via confocal laser scanning microscopy (CLSM). The use of multiwelled petri dishes allowed for assessment of large numbers of roots in small volumes of labeling solutions of $500 \mu \mathrm{L}$ or less. Root hairs could also be treated with wall-degrading enzymes to remove and unmask specific polymers prior to labeling $[28,29]$. We also tested root hair viability, labeling quality/intensity with and without the inclusion of a detergent $(0.85 \mathrm{mM}$ Triton-X100) in the labeling protocol and noted no discernable difference in labeling results. Control experiments also showed that the labeling was specific.

Table 1 provides a summary of antibodies used and labeling results that were obtained for the following phenotypes: wild-type (wt), the vti13 single mutant, prp3 single mutant, the prp3 vti13 double mutant, $c s d l 2$ single mutant, the $c s d l 3-2$ double mutant and the $x x t 1, x x t 2$ and $x x t 5$ single mutants. In wt root hairs, intense labeling was noted for mAbs specific for epitopes of xyloglucan, xylan and arabinogalactan protein with moderate labeling for extensin and homogalacturonan (HG), specifically low esterified HG. Similar results were observed for the prp3 mutant walls. In vti13 seedlings, xyloglucan- and xylan-epitope labeling was absent in root hairs. For the double mutant, prp3 vti13, xyloglucan and xylan labeling was present in root hairs. The csld2-1 mutant produced notably small root hairs [30] while the csld3-2 mutant produced no root hairs [30]. The csld2-1 mutant had similar labeling to the wt except for the absence of LM19-probed HG and LM11-probed ß(1-4)-xylan/arabinoxylan. The $x x t$ mutants yielded similar results except for the lack of LM10 labeling in the $x x t 1$ line. Most notable though was the complete lack of labeling with the xyloglucan probes, LM15 and LM25 in all three mutant lines. These results provide evidence that differences in root hair cell wall organization or composition in different genetic backgrounds can be used to identify root hair mutant phenotypes in live seedlings.

For detailed analysis of imaging, we chose the xylosylated-xyloglucan specific mAb, LM15 [29]. LM15 labeled the root hairs and epidermis of the wt root (Figure 2A, B) with a subtle gradient of higher labeling at the tip and lesser intensity at the base (Figure 2C). 


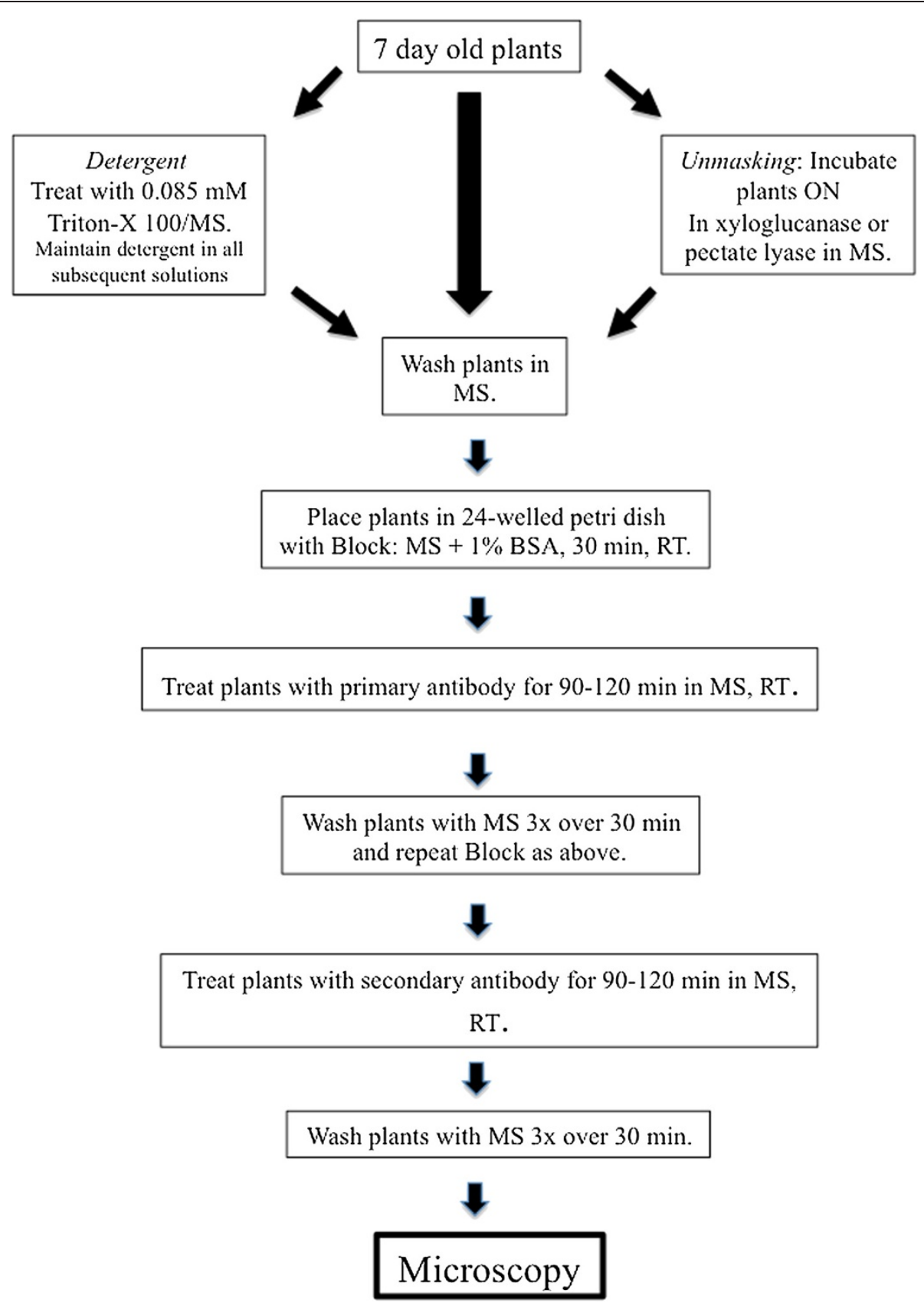

Figure 1 Schematic outline of live cell labeling protocol.

No discernable difference was noted in labeling when the protocol included the detergent-containing base, MS-Tri-X100 (Figure 2E, F). When pre-treated with $5 \mathrm{U}$ of xyloglucanase for $90 \mathrm{~min}$, the root hairs did not label with LM15 (Figure 2G, H). When pre-treated with $3 \mathrm{U}$ of pectate lyase for $90 \mathrm{~min}$, LM15 labeling was unaltered (Figure 2I, J). TEM immunogold labeling supplemented our CLSM imaging and demonstrated that LM15 labeling was indeed localized at the cell wall (Figure 2K). A control experiment whereby the primary antibody was eliminated from the protocol showed no labeling (Figure 2L, M). LM15 labeled the cell walls of the root hairs of the prp3 mutant (Figure 3A, B). LM15 did not label the root hairs of the vti13 mutant (Figure 3C, D) but did label the double mutant, prp3 vti13 (Figure 3E, F).

LM10, a mAb with specificity toward xylan, labeled the root hairs of the WT, prp3 and double mutant, prp3 vti13, but not the vti13 mutant (Figure 4A, D, G, H). Labeling of pectin with relative low levels of esterification using LM19 demonstrated that labeling was present in all 
Table 1 Summary of antibodies employed and results of immunocytochemical labeling

\begin{tabular}{|c|c|c|c|c|c|c|c|c|c|c|}
\hline mAb & Specificity/Reference & WT & vti13 & prp3 & prp3/vti13 & csld2 & csld3-2 & xxt1 & xxt2 & xxt5 \\
\hline \multicolumn{11}{|l|}{ PECTINS } \\
\hline JIM7 & High DE HG [31] & - & - & - & - & - & NA & - & - & - \\
\hline LM19 & Low DE HG [23] & ++ & ++ & + & ++ & - & NA & + & + & + \\
\hline LM5 & (1-4)-galactan [32] & - & - & - & - & - & NA & - & - & - \\
\hline LM6 & (1-5)-arabinan [33] & - & - & - & - & - & NA & - & - & - \\
\hline INRA-RU1 & Rhamnogalacturonan-I [34] & - & - & - & - & - & NA & - & - & - \\
\hline \multicolumn{11}{|c|}{ XYLOGLUCAN } \\
\hline LM15 & xylosylated XyG [29] & ++ & - & ++ & ++ & + & NA & - & - & - \\
\hline LM25 & galactosylated XyG epitope [20] & ++ & - & + & ++ & + & NA & - & - & - \\
\hline \multicolumn{11}{|l|}{ MANNAN } \\
\hline BS-400-4 & B(1-4)-mannan/galacto-ß(1-4)-mannan [35] & - & - & - & - & - & NA & - & - & - \\
\hline \multicolumn{11}{|l|}{$X Y L A N$} \\
\hline LM10 & (1-4)-xylan [36] & ++ & - & ++ & ++ & ++ & NA & - & ++ & ++ \\
\hline LM11 & B(1-4)-xylan/arabinoxylan [36] & + & - & + & + & - & NA & - & - & - \\
\hline \multicolumn{11}{|l|}{$A G P$} \\
\hline LM2 & AGP [37] & - & - & - & - & - & NA & - & - & - \\
\hline JIM13 & AGP [38] & + & + & + & + & + & NA & + & + & + \\
\hline JIM8 & AGP [39] & + & + & + & + & + & NA & + & + & - \\
\hline \multicolumn{11}{|l|}{ EXTENSIN } \\
\hline LM1 & Extensin [40] & ++ & ++ & + & ++ & + & NA & + & + & + \\
\hline JIM20 & Extensin [41] & + & + & + & + & + & NA & + & + & + \\
\hline
\end{tabular}

Key: $++=$ intense labeling, $+=$ moderate labeling, $-=$ ss no label, NA = not applicable, no root hairs formed.

genotypes (Figure 4B, E, I; Table 1). Interestingly, JIM7, a mAb with specificity toward high-esterified HG, did not label the root hairs of any of the tested genetic backgrounds (e.g. Figure 4C; Table 1). Previous studies, using fixed sections of plant roots have shown that both JIM5 and JIM 7 label the cell walls of root hairs [42]. These results suggest that the pectin epitopes recognized by JIM5 and JIM7 may not be accessible to the antibody in growing root hairs when using live seedlings. JIM20, a mAb with specificity toward extensin, labeled the root hairs of all genotypes as exemplified by vti13 (Figure 4F; Table 1). These results help define the dynamics of the root hair cell wall and how organization or composition is altered in root hair mutants, prp3 and vti13.

These methods were then used to investigate the root hairs of mutant lines defective in the synthesis of structural carbohydrates within the cell wall. The csld2-1 mutant produced small root hairs that labeled inconsistently with LM15 or LM25. The developing root hairs near the root tip labeled but no label was noted in fully expanded hairs further removed from the root tip (Figure 5A-C). No hairs were formed in the csld3-2 line as has been previously described [31,43-45], but it is important to note that LM15/LM25 labeling was noted in the epidermis (Figure $5 \mathrm{D}, \mathrm{E}$ ). For the $x x t$ mutant lines, root hairs were present but did not label with either LM15 or 25, as illustrated for $x x t 1$ (Figure $5 F, G$ ). In summary, the results of this study highlight a convenient and simple means to identify other cell wall mutant lines and better define changes in their wall microarchitecture.

\section{Discussion}

Live cell labeling of root hairs of Arabidopsis provides a valuable new tool in elucidating wall microarchitecture and development. This simple and relatively fast method of mapping specific wall polymers offers much potential in adding detail to cell wall deposition/organization and cell expansion dynamics. In this study, we demonstrated labeling of xyloglucans in the root hairs of WT, prp3 single mutant and the double mutant, prp3 vti13 using the xylosylated-xyloglucan specific mAb, LM15, and the galactosylated xyloglucan specific mAb, LM25. These observations supplement recent research where a galacturonic acid-containing xyloglucan is found in Arabidopsis root hair cell walls [18]. Likewise, we show a higher intensity labeling at the root tip in our study with LM15 in WT and prp3 vti13 double mutant root hairs compared to the labeling in the vti13 single mutant, which has a branching root hair phenotype under our growth conditions [46]. This observation suggests that xyloglucan 


\section{LM15 Wild type}
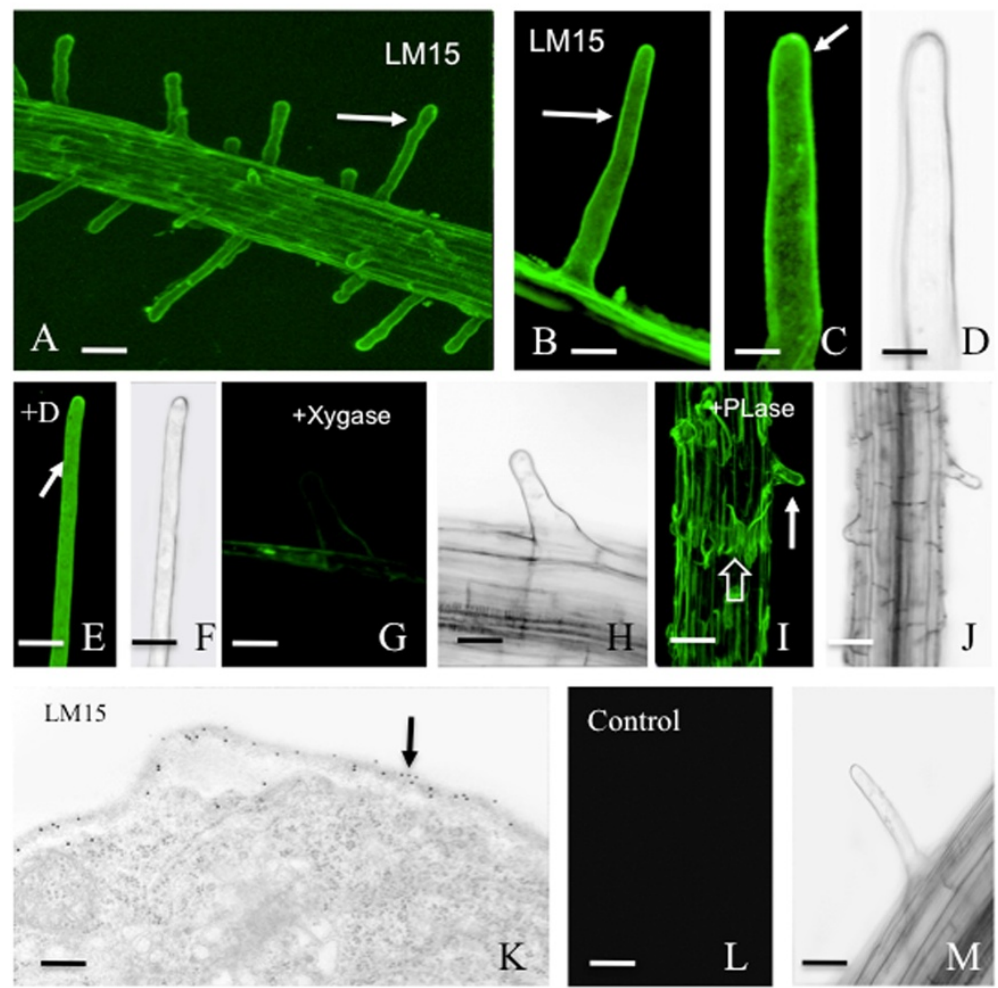

Figure 2 Live cell LM15 labeling of wild type (wt) Arabidopsis root hairs. A: Overview of live root demonstrating strong LM15 labeling of root hairs (arrows) and epidermis (hollow arrow). Bar $=100 \mu \mathrm{m}$. B: Magnified view of a root hair labeled with LM15 (arrow). Bar $=19 \mu \mathrm{m}$. C and D: LM15 labeling of root hair highlighting a slight but notable gradient with more intense labeling at the root hair tip (C, arrow). D is the DIC profile of $C$. Bars for $C$ and $D=12 \mu \mathrm{m}$. E and $\mathbf{F}$ : LM15 labeling of root hair ( $E$, arrow) after incubation of root in $0.085 \mathrm{mM}$ Triton-X detergent (+D), during labeling process. Note labeling of root hair is comparable to that observed with non-detergent labeling (A-C). F is the DIC profile of E. Bars for $E$ and $\mathrm{F}=30 \mathrm{\mu m}$. G and $\mathbf{H}$ : LM15 labeling after root was pre-incubated overnight in $5 \mathrm{U}$ of xyloglucanase (+Xygase). Note the lack of labeling of root and hairs $(\mathrm{G})$. $\mathrm{H}$ is the DIC profile of $\mathrm{G}$. Bars for $\mathrm{G}$ and $\mathrm{H}=18 \mu \mathrm{m}$. I and $\mathbf{J}$ : $\mathrm{LM} 15$ labeling after root was pre-incubated overnight in $3 \mathrm{U}$ of pectate lyase (+PLase). Note that the root hair labels (I, solid arrow). The epidermal cells labeling appears in strips (I, hollow arrow) but still labels. J is the DIC profile of I. Bars for I and J = 50 um. K: Immunogold profile of root hair cell wall labeled with LM15 (arrow), Bar $=50 \mathrm{~nm}$. L and $\mathbf{M}$ : Control profile whereby the primary antibody was eliminated during labeling. $M$ is the DIC profile of $L$. Bars for $L$ and $M=30 \mu m$.

polymers may play a key role in providing controlled tensile resistance to turgor pressure at the root hair tip during growth. This tensile support might be especially important in this zone where less organized cellulose microfibril organization has been noted [12]. Our study has also shown that wall glycoproteins such as extensin and arabinogalactan proteins can be detected in the root hair wall of live seedlings, supporting recent work that also showed the presence of these polymers in the wall $[19,47,48]$.

In the Arabidopsis root hair, xyloglucan and other hemicellulosic polymers like xylan may also be critical to regulating wall extensibility. The absence of labeling of certain epitopes in the vti13 single mutant and the recovery of these labeling patterns in the prp 3 vti13 double mutant suggests that there is a reorganization of the cell wall matrix in vti13 root hairs, rather than a loss of these components from the cell wall. Therefore, the vti13 mutant has an altered deposition or development of the cell wall such that the epitopes are not available to the mAb labeling. The reemergence of the epitopes in the prp3 $v t i 13$ is evidence that the cell wall has gone through another reorganization, not a loss of specific constituents of the matrix.

Our results also show that this methodology can also be used for studying wall mutant lines, especially those deficient in the synthesis of specific wall polymers. The $x x t$ mutants did not label with LM15 or LM25, antibodies specific for xyloglucan epitopes. Genetic analysis of $x x t 1$ and $x x t 2$ mutants has shown that xyloglucan synthesis is required for root hair growth $[42,49]$. In addition, similar amounts of xyloglucan can be detected within the walls of wt and single $x x t 1$ and $x x t 2$ mutant seedlings using OLIMP analysis, suggesting that these two loci compensate for one other during xyloglucan synthesis [42]. The lack of labeling of root hairs in $x x t$ mutant seedlings with LM15/LM25 in this study 


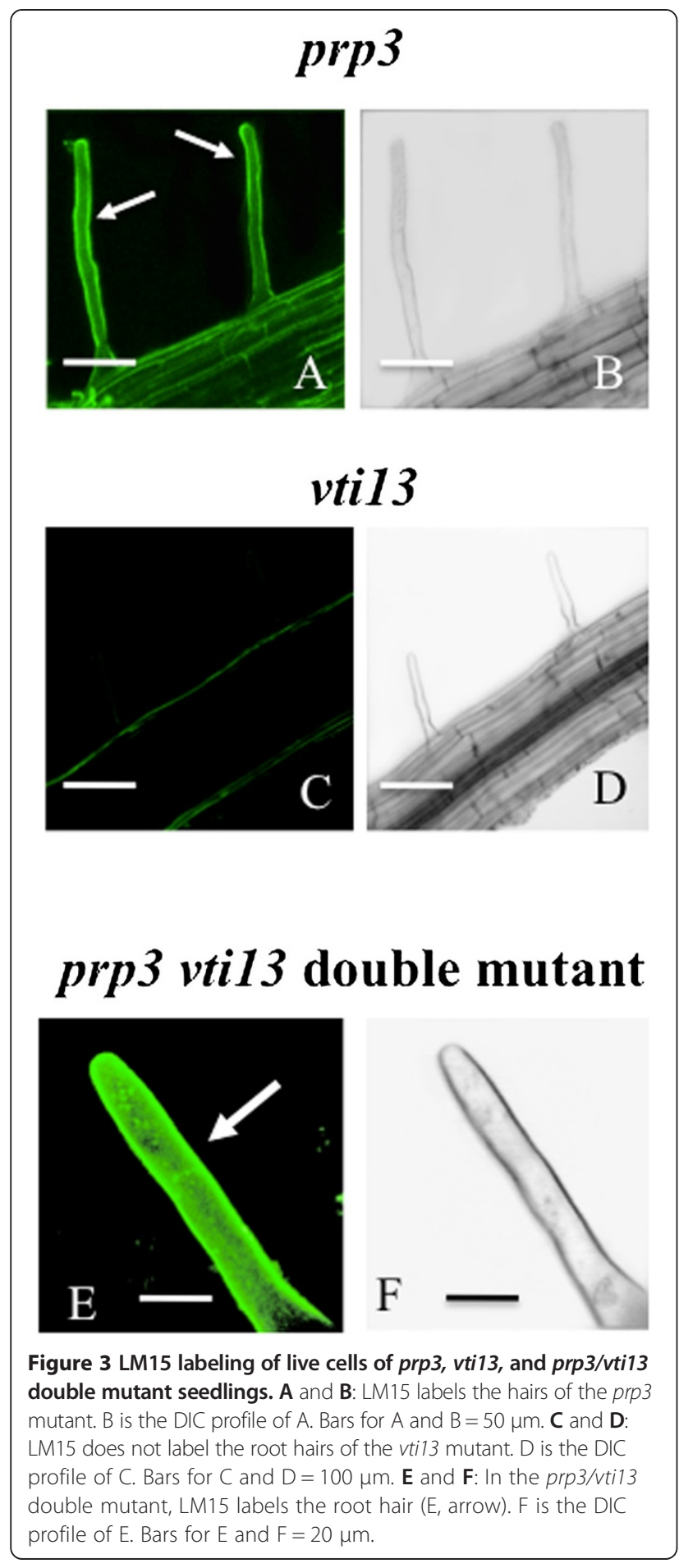

suggests subtle changes in xyloglucan orientation within the wall may eliminate the availability of the LM15 and LM25 epitopes using live seedlings. For the csld mutants, lines deficient in the synthesis of $ß$-glucans (e.g. mannose, cellulose; $[30,50,51])$, the results were limited as the two lines either did not produce root hairs or yielded small hairs with inconsistent labeling. Overall, the ability to discern these nuances of cell wall metabolism makes this live labeling protocol a powerful tool in defining phenotypes in cell wall and root hair mutants. A next step in expanding use of this method will be labeling with two or more wall-specific mAbs.

\section{Conclusion}

Live cell labeling of cell wall epitopes allows for dynamic imaging of wall structure during development as well as important application for co-labeling studies. For example, using this methodology along with fluorescent protein-fusion constructs of various components of the secretory and cytoskeletal machinery of the hair offer powerful and specific mechanisms for deciphering the coordinated interactions of specific subcellular systems in the development of the cell wall and constituent polymers therein.

\section{Methods}

\section{General}

Seeds of wt and various Arabidopsis mutants (all in a Columbia background) were surface sterilized with a $20 \%(\mathrm{v} / \mathrm{v})$ bleach solution and sown on MS medium (1X Murashige and Skoog salts, 1\% (w/v) sucrose, 1X Gamborg's vitamin solution, $5 \mathrm{mM}$ MES pH6) and solidified with $1.3 \%(\mathrm{w} / \mathrm{v})$ agarose as described in Larson et al. [36]. The vti13 mutant (SALK_075261) was obtained from the Arabidopsis Biological Research Center (ABRC) and confirmed to be a null mutant. The prp3 and vti13 single mutants were crossed using standard procedures and the homozygous double mutant was identified in the F2 generation using genomic PCR (described in [36]). CSLDand XXT-mutant lines were a generous gift of Dr. Ken Keegstra. Murashige-Skoog (MS) medium was obtained from Sigma Chemical (St. Louis, MO, USA) and antibodies were obtained from Plant Probes (Leeds, UK), Sigma Chemical (St. Louis, MO, USA) and a generous gift from Dr. Marie Christine-Ralet (INRA, Nantes, FR).

\section{Immunofluorescence labeling}

All labeling was performed in a 24-welled petri dish (nontissue culture treated dishes; Fisher Scientific, Pittsburg, PA, USA). Arabidopsis seedlings were grown vertically on MS-containing media for 7 days after which they were gently removed from the agarose surface, placed in the wells of the petri dish and incubated for $30 \mathrm{~min}$ in $500 \mu \mathrm{L}$ of liquid MS medium containing $1.0 \%(\mathrm{w} / \mathrm{v})$ non-fat Carnation Instant milk. This represented the blocking solution for immunolabeling. In an initial test of labeling quality and root hair viability, we compared samples processed in MS as the buffer for labeling with samples processed in MS and detergent $(0.85 \mathrm{mM}$ Triton-X100). No difference was noted between the two solutions and the inclusion of detergent was 


\section{Wild type}
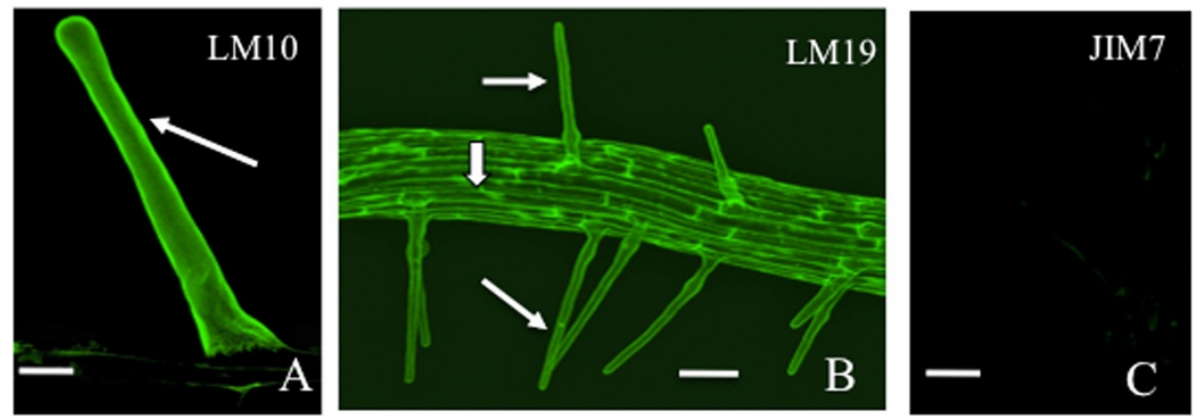

\section{vti13}
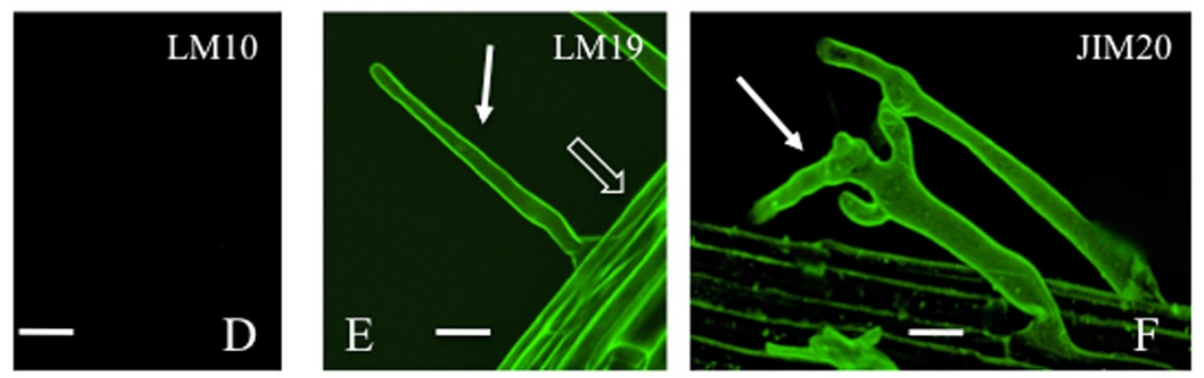

\section{prp3}

prp3 vtil3
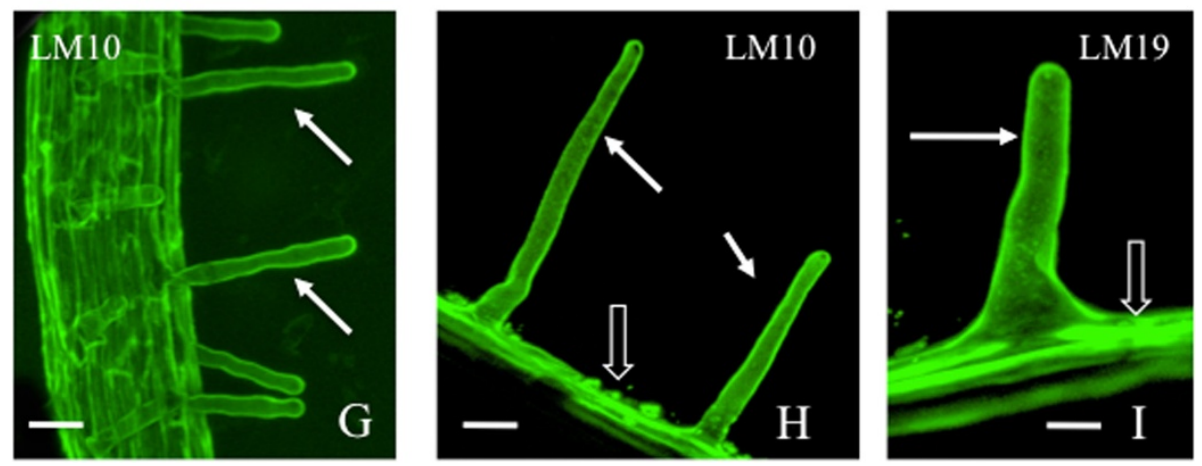

Figure 4 Live cell profiles of immunolabeled root hairs. A: LM10 labeling of a wt root hair (arrow). Bar $=10 \mu \mathrm{m}$. B: LM19 labeling of wt root hairs (solid arrows) and root epidermis (hollow arrow). Bar $=80 \mu \mathrm{m}$. C: Lack of JIM7 labeling of wt root hairs. Bar $=20 \mu \mathrm{m}$. D: The root hairs of the vti13 mutant do not label with LM10. Bar $=30 \mu \mathrm{m}$. E: LM19 labeling of vti13 root hairs (solid arrow) and root epidermis (hollow arrow). Bar $=35 \mu \mathrm{m}$. F: JIM 20 labeling of root hairs of the vti13 (arrow). Bar $=15 \mu \mathrm{m}$. G: LM10 labeling of root hairs (arrows) of prp3 mutant. Bar = $15 \mu \mathrm{m}$. H: LM10 labeling of root hairs of prp3/vti13 (solid arrows) and root epidermis (hollow arrow). Bar $=15 \mu \mathrm{m}$. I: LM19 labeling of root hairs of prp3/vti13 (solid arrows) and root epidermis (hollow arrow). Bar $=10 \mu \mathrm{m}$.

maintained for all subsequent labeling and is noted as MS-Tri-X100 below. After blocking, the seedlings were washed 3X over 30 min with liquid MS medium and then placed in $500 \mu \mathrm{L}$ of primary antibody solution that consisted of a $1 / 10(\mathrm{v} / \mathrm{v})$ dilution of wall polymer- specific antibody in MS-Tri-X100. Plates were gently shaken on a laboratory rotator for $90 \mathrm{~min}$ in the dark at Room Temperature (RT). Seedlings were again washed $3 \mathrm{X}$ with MS-Tri-X100, blocked (as described above) and washed again. Seedlings were incubated and gently 


\section{csld 2}
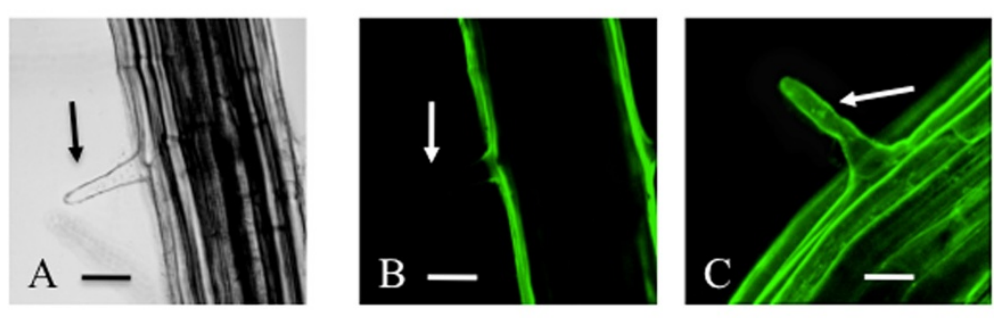

csld3-2
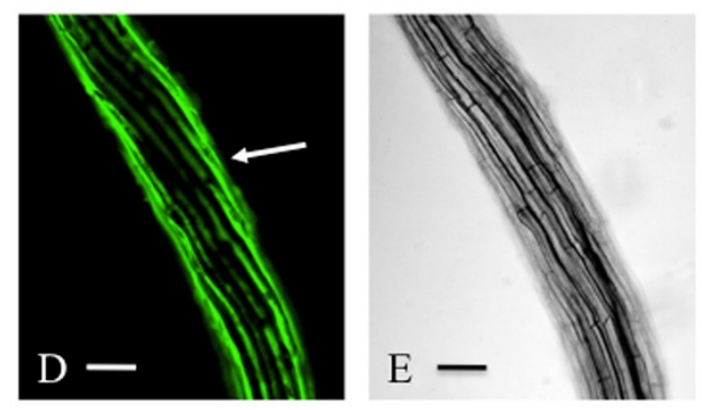

$x x t 1$
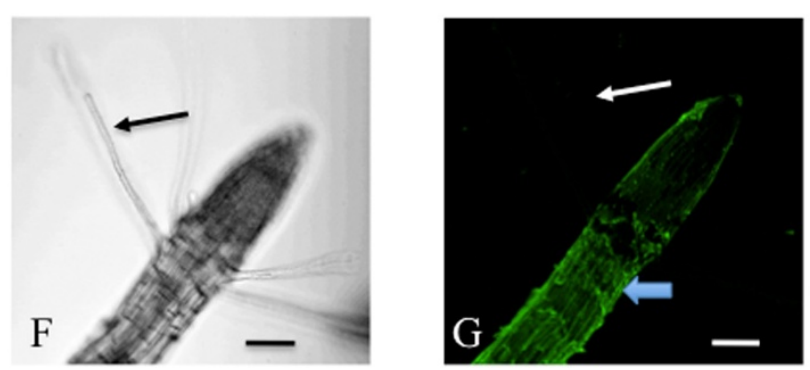

Figure $\mathbf{5}$ Live cell profiles of immunolabeled root hairs of cell wall mutant lines. A: A small root hair of the cs/d-2 line located approximately $2 \mathrm{~mm}$ from the root tip. Bar $=20 \mu \mathrm{m}$. B: LM15 labeling of the root hair identified in "A". Note the absence of labeling (arrow). Bar $=20 \mu \mathrm{m}$. C: LM15 labeling of a small root hair (arrow) located just behind the root tip of the cs/d2 mutant. Bar = $12 \mu \mathrm{m}$. D: No root hairs were found in the cs/d3-2 mutant but the epidermis labeled with LM15 (arrow). Bar $=20 \mu \mathrm{m}$. E: DIC image of the root shown in "D". Bar = $20 \mu \mathrm{m}$. F: The root hairs of the xxt1 mutant line (arrow). Bar = $30 \mu \mathrm{m}$. G: LM15 labeling of the root hairs (arrow) observed in "F". Bar = $15 \mu \mathrm{m}$.

shaken for $90 \mathrm{~min}$ in the dark at RT in $500 \mu \mathrm{L}$ of a $1 / 75$ $(\mathrm{v} / \mathrm{v})$ dilution of secondary antibody (anti-rat-TRITC; Sigma) in MS-Tri-X100. They were then washed with liquid MS 3X over $30 \mathrm{~min}$. The seedlings were left in MS liquid medium until microscopic viewing. For control, primary antibody labeling was eliminated from the protocol. For each primary antibody tested at least 1015 root hairs of 3 separate seedlings were observed. This process was also performed three times.

For unmasking experiments, some seedlings were gently shaken in solutions of $5 \mathrm{U}$ xyloglucanase (Megazyme, IR) or $3 \mathrm{U}$ pectolyase (Megazyme) in MS for $90 \mathrm{~min}$ at
RT. The seedlings were then removed, washed $3 \mathrm{X}$ with MS and processed for labeling (see above).

The labeled seedlings were placed in a $200 \mu \mathrm{L}$ drop of liquid MS in the well of a single-welled immunoslide (EMS, Ft. Washington, PA, USA). A glass coverslip was placed gently over the seedling. The depression of the immunoslide prevented crushing of the root and hairs. For some slides, the coverslip was affixed to the slide with small drops of nail polish. Root hairs were then observed using an Olympus BX-61 microscope equipped with a Fluoview 300 confocal system. The fluorescence signals were also observable using wide field Olympus 
BX-60 or IX70 fluorescence microscopes with 50 watt mercury lamp[s and TRITC filter sets.

\section{Transmission Electron Microscopy (TEM)}

Roots were fixed in $0.5 \%(\mathrm{v} / \mathrm{v})$ glutaraldehyde (EMS, Ft. Washington, PA, USA) in Sorensen's Phosphate buffer (EMS; $\mathrm{pH} 7.2$ ) for $40 \mathrm{~min}$ at $4^{\circ} \mathrm{C}$. They were washed $3 \mathrm{X}$ with Sorensen's buffer and post-fixed in $0.5 \%(\mathrm{w} / \mathrm{v})$ $\mathrm{OsO}_{4}$ (EMS) in Sorensen's buffer for $1 \mathrm{~h}$ at $4^{\circ} \mathrm{C}$. After washing with buffer (see above), the seedlings were dehydrated in acetone and embedded in Spurrs Low Viscosity plastic. $60-80 \mathrm{~nm}$ sections were obtained using a Reichert Ultracut ultramicrotome and collected on formvar coated nickel grids. Immunogold labeling was performed using previously developed techniques [52].

\section{Competing interests}

The authors declare that they have no competing interests.

\section{Authors' contributions}

All authors participated in the design of this study as well as immunofluorescence labeling of the root hairs. DSD performed the TEM. All authors read and approved the final manuscript.

\section{Acknowledgements}

This work was supported by grants the National Science Foundation to DSD (NSF-MCB 0919925 and NSF-DBI 0922805).

\section{Author details}

${ }^{1}$ Cellular, Molecular, and Biomedical Science Program, University of Vermont, Burlington, VT, USA. ${ }^{2}$ Department of Plant Biology, University of Vermont, Burlington, VT, USA. ${ }^{3}$ Department of Biology, Skidmore College, Saratoga Springs, NY, USA. ${ }^{4}$ Laboratory of Plant Physiology and Biophysics, Institute of Molecular Cell and Systems Biology, Bower Building, University of Glasgow, Glasgow G12 8QQ, UK.

Received: 31 March 2014 Accepted: 23 September 2014

Published: 2 October 2014

\section{References}

1. Geitmann A: How to shape a cylinder: Pollen tube as a model system for the generation of complex cellular geometry. Sex Plant Reprod 2010, 23:63-71.

2. Chebli Y, Geitmann A: Mechanical properties governing pollen tube growth. Funct Plant Sci Biotech 2007, 1:232-245.

3. Ivakov A, Persson S: Plant cell shape: modulators and measurements. Front Plant Sci 2013. doi:10.3389/fpls.2013.00439.

4. Domozych DS, Fujimoto C, LaRue T: Polar expansion dynamics in the plant kingdom: A diverse and multifunctional journey on the path to pollen tubes. Plants 2013, 2:148-173.

5. Hepler PK, Rounds CM, Winship L: Control of cell wall extensibility during pollen tube growth. Mol Plant 2013, 6:998-1017.

6. Chebli Y, Kaneda M, Zerzour R, Geitmann A: The cell wall of the Arabidopsis thaliana pollen tube- Spatial distribution, recycling and network formation of polysaccharides. Plant Physiol 2012, 160:1940-1955.

7. Palin R, Geitmann A: The role of pectin in plant morphogenesis. BioSyst 2012, 109:397-402

8. Mollet J-C, Leroux C, Dardelle F, Lehner A: Cell wall composition, biosynthesis and remodeling during pollen tube growth. Plants 2013, 2:107-147.

9. Leitner D, Klepsch S, Ptashnyk M, Marchant A, Kirk GJD, Schnepf A, Roose T: A dynamic model of nutrient uptake by root hairs. New Phytol 2010, 185:792-802.

10. Schmidt W, Schikora A: Different pathways are involved in phosphate and iron stress-induced alterations of root epidermal cell development. Plant Physiol 2001, 125:2078-2084.

11. Bates TR, Lynch JP: The efficiency of Arabidopsis thaliana (Brassicaceae) root hairs in phosphorus acquisition. Am J Bot 2000, 87:964-970.
12. Akkerman M, Franssen-Verheijen MAW, Immerzeel P, Hollander LDEN, Schel $J H N$, Emons AMC: Texture of cellulose microfibrils of root hair cell walls of Arabidopsis thaliana, Medicago truncatula, and Vicia sativa. J Microsc 2012, 247:60-67.

13. Dumais J, Shaw SL, Steele CR, Long SR, Ray PM: An anisotropic-viscoplastic model of plant cell morphogenesis by tip growth. Int I Dev Biol 2006, 50:209-222

14. Emons AMC, Ketelaar T: Intracellular organization: A prerequisite for root hair elongation and cell wall deposition. In Plant Cell Monographs: Root Hairs. Edited by Emons AMC, Ketelaar T. Berlin: Springer; 2009:27-44.

15. Galway ME: Root hair cell walls: filling in the framework. Can J Bot 2006, 84:613-621.

16. Nielsen E: Plant cell wall biogenesis during tip growth in root hair cells. In Plant Cell Monographs: Root Hairs. Edited by Emons AMC, Ketelaar T. Berlin: Springer; 2009:85-102.

17. Shaw SL, Dumais J, Long SR: Cell Surface Expansion in Polarly Growing Root Hairs of Medicago truncatula. Plant Physiol 2000, 124:959-970.

18. Peña MJ, Kong Y, York WS, O'Neill MA: A galacturonic acid-containing xyloglucan is involved in Arabidopsis root hair tip growth. Plant Cell 2012, 24:4511-4524

19. Velasquez SM, Ricardi MM, Dorosz JG, Fernandez PV Nadra AD, Pol-Fachin L, Egelund J, Gille S, Harholt J, Ciancia M, Verli H, Pauly M, Bacic A, Olsen CE, Ulvskov P, Petersen BL, Somerville C, lusem ND, Estevez JM: O-Glycosylated Cell Wall Proteins Are Essential in Root Hair Growth. Science 2011, 332:1401-1403.

20. Pedersen HL, Fangel JU, McCleary B, Ruzanski C, Rydahl MG, Ralet M-C, Farkas V, von Schantz L, Marcus SE, Andersen MCF, Field R, Ohlin M, Knox JP, Clausen MH, Willats WGT: Versatile high-resolution oligosaccharide microarrays for plant glycobiology and cell wall research. J Biol Chem 2012, 287:39429-39438.

21. Moller I, Marcus SE, Haeger A, Verhertbruggen $Y$, Verhoef $R$, Schols $H$, Mikklesen JD, Knox JP, Willats W: High-throughput screening of monoclonal antibodies against plant cell wall glycans by hierarchial clustering of their carbohydrate microarray binding profiles. Glycoconj J 2008, 25:37-48.

22. Hervé C, Marcus SE, Knox JP: Monoclonal antibodies, carbohydrate-binding modules, and the detection of polysaccharides in plant cell walls. In The Plant Cell Wall: Methods and Protocols, Methods in Molecular Biology, vol. 715. Edited by Popper ZA. New York: Springer/Humana Press; 2011:103-113.

23. Verhertbruggen Y, Marcus SE, Haeger A, Ordaz-Ortiz JJ, Knox JP: An extended set of monoclonal antibodies to pectic homogalacturonan. Carbohydr Res 2009, 344:1858-1862.

24. Talboys PJ, Zhang HM, Knox JP: ABA signalling modulates the detection of the LM6 arabinan cell wall epitope at the surface of Arabidopsis thaliana seedling root apices. New Phytol 2011, 190:618-626.

25. Lee KJD, Knox JP, Žárský V, CVrckova F: Resin embedding, sectioning and immunocytochemical analyses of plant cell walls in hard tissues. In Plant Cell Morphogenesis: Methods and Protocols, Methods in Molecular Biology, Vol. 1080. New York: Springer / Humana Press; 2013:41-52.

26. Domozych DS, Brechka H, Britton A, Toso M: Cell wall growth and modulation dynamics in a model unicellular green alga - Penium margaritaceum: live cell labeling with monoclonal antibodies. J Bot 2011 doi:10.1155/2011/632165

27. Domozych DS, Lambiasse L, Kiemle SN, Gretz MR: Cell wall development and bipolar growth in the desmid Penium margaritaceum. Asymmetry in a symmetric world. J Phycol 2009, 45:879-893.

28. Hervé C, Rogowski A, Gilbert HJ, Knox JP: Enzymatic treatments reveal differential capacities for xylan recognition and degradation in primary and secondary plant cell walls. Plant J 2009, 58:413-422.

29. Marcus SE, Verhertbruggen Y, Herve C, Ordaz-Ortiz JJ, Farkas V, Pedersen HL, Willats WGT, Knox JP: Pectic homogalacturonan masks abundant sets of xyloglucan epitopes in plant cell walls. BMC Plant Biol 2008, 8:60-71.

30. Bernal AJ, Yoo CM, Mutwil M, Jensen JK, Hou G, Blaukopf C, Sørensen L, Blancaflor EB, Scheller HV, Willats WGT: Functional analysis of the cellulose synthase-like genes Csld1, Csld2, and Csld4 in tip-growing Arabidopsis cells. Plant Physiol 2008, 148:1238-1253.

31. Clausen MH, Willats WGT, Knox JP. Synthetic methyl hexagalacturonate hapten inhibitors of anti-homogalacturonan monoclonal antibodies LM7, JIM5 and JIM7. Carbohydr Res 2003, 338:1797-1800.

32. Jones L, Seymour GB, Knox JP: Localization of pectic galactan in tomato cell walls using a monoclonal antibody specific to (1-> 4)-beta-D-galactan Plant Physiol 1997, 113:1405-1412 
33. Willats WGT, Marcus SE, Knox JP: Generation of a monoclonal antibody specific to (1-> 5)-alpha-L-arabinan. Carbohydr Res 1998, 308:149-152.

34. Ralet M-C, Tranquet O, Poulain D, Moïse A, Guillon F: Monoclonal antibodies to rhamnogalacturonan I backbone. Planta 2010, 231:1373-1383.

35. Pettolino FA, Hoogenraad NJ, Ferguson C, Bacic A, Johnson E, Stone BA: A (1-4)-beta-mannan-specific mono- clonal antibody and its use in the immunocytochemical location of galactomannans. Planta 2001, 214:235-242.

36. McCartney L, Marcus SE, Knox JP: Monoclonal antibodies to plant cell wall xylans and arabinoxylan. J Histochem Cytochem 2005, 53:543-546.

37. Smallwood M, Yates EA, Willats WGT, Martin H, Knox JP: Immunochemical comparison of membrane associated and secreted arabinogalactanproteins in rice and carrot. Planta 2006, 198:452-459.

38. Yates EA, Valdor J-F, Haslam SM, Morris HR, Dell A, Mackie W, Knox JP: Characterization of carbohydrate structural features recognized by anti-arabinogalactan-protein monoclonal antibodies. Glycobiol 1996, 6:131-139.

39. McCabe PF, Valentine TA, Forsberg LS, Pennell Rl: Soluble signals from cells identified at the cell wall establish a developmental pathway in carrot. Plant Cell 1997, 9:2225-2241.

40. Smallwood M, Beven A, Donovan N, Neill SJ, Peart J, Roberts K, Knox JP: Localization of cell wall proteins in relation to the developmental anatomy of the carrot root apex. Plant J 1994, 5:237-246.

41. Xu C, Takac T, Burbach C, Menze D, Samaj J: Developmental localization and the role of hydroxyproline rich glycoproteins during somatic embryogenesis of banana (Musa spp. AAA). BMC Plant Biol 2011, 11:38.

42. Cavalier DM, Lerouxel O, Neumetzler L, Yamauchi K, Reinecke A, Freshour G, Zabotina OA, Hahn MG, Burgert I, Pauly M, Raikhel NV, Keegstra K: Disrupting two Arabidopsis thaliana xylosyltransferase genes results in plants deficient in xyloglucan, a major primary cell wall component. Plant Cell 2008, 20:1519-1537.

43. Galway ME, Eng RC, Schiefelbein JW, Wasteneys GO: Root hair-specific disruption of cellulose and xyloglucan in AtCSLD3 mutants, and factors affecting the post-rupture resumption of mutant root hair growth. Planta 2011, 233:985-999.

44. Favery B, Ryan E, Foreman J, Linstead P, Boudonck K, Steer M, Shaw P, Dolan L: KOJAK encodes a cellulose synthase-like protein required for root hair cell morphogenesis in Arabidopsis. Genes Dev 2001, 15:79-89.

45. Wang X, Cnops G, Vanderhaeghen R, De Block S, Van Montagu M, Van Lijsebettens M: AtCSLD3, a cellulose synthaselike gene important for root hair growth in Arabidopsis. Plant Physiol 2001, 126:575-586.

46. Larson ER, Domozych DS, Tierney ML: SNARE VTI13 plays a unique role in endosomal trafficking pathways associated with the vacuole and is essential for cell wall organization and root hair growth in Arabidopsis. Ann Bot 2014. in press.

47. Baumberger N, Ringli C, Keller B: The chimeric leucine rich repeat/extensin cell wall protein $L R X 1$ is required for root hair morphogenesis in Arabidopsis thaliana. Genes Dev 2001, 15:1128-1139.

48. Nguema-Ona E, Coimbra S, Vicré-Gibouin M, Mollet J-C, Driouich A: Arabinogalactan proteins in root and pollen-tube cells: distribution and functional aspects. Ann Bot 2012, 110:383-404.

49. Zabotina OA, Wilhelmina TG, Van De V, Freshour G, Drakakaki G, Cavalier D, Mouille G, Hahn MG, Keegstra K, Raikhe NV: Arabidopsis XXT5 gene

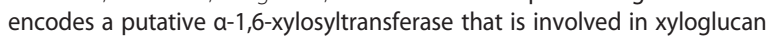
biosynthesis. Plant J 2008, 56:101-115.

50. Park S, Szumlanski AL, Gu F, Guo F, Nielsen E: A role for CSLD3 during cell-wall synthesis in apical plasma membranes of tip-growing root-hair cells. Nat Cell Biol 2011, 13:973-980.

51. Yo C-M, Quan L, Blacaflor EB: Divergence and redundancy in CSLD2 and CSLD3 function during Arabidopsis thaliana root hair and female gametophyte development. Front Plant Sci 2011. doi: 10.3389/fpls.2012.00111.

52. Baylson FA, Stevens BW, Domozych DS: Composition and synthesis of pectin and protein components of the cell wall of Closterium acerosum (Chlorophyta). J Phycol 2001, 37:796-809.

doi:10.1186/1746-4811-10-30

Cite this article as: Larson et al:: Using monoclonal antibodies to label living root hairs: a novel tool for studying cell wall microarchitecture and dynamics in Arabidopsis. Plant Methods 2014 10:30.

\section{Submit your next manuscript to BioMed Central and take full advantage of:}

- Convenient online submission

- Thorough peer review

- No space constraints or color figure charges

- Immediate publication on acceptance

- Inclusion in PubMed, CAS, Scopus and Google Scholar

- Research which is freely available for redistribution 